University of Nebraska - Lincoln

DigitalCommons@University of Nebraska - Lincoln

Faculty Papers and Publications in Animal

Science

Animal Science Department

April 1999

\title{
Implications of Cloning for Breed Improvement Strategies: Are Traditional Methods of Animal Improvement Obsolete?
}

\author{
L. Dale Van Vleck \\ University of Nebraska-Lincoln, dvan-vleck1@unl.edu
}

Follow this and additional works at: https://digitalcommons.unl.edu/animalscifacpub

Part of the Animal Sciences Commons

Van Vleck, L. Dale, "Implications of Cloning for Breed Improvement Strategies: Are Traditional Methods of Animal Improvement Obsolete?" (1999). Faculty Papers and Publications in Animal Science. 284.

https://digitalcommons.unl.edu/animalscifacpub/284

This Article is brought to you for free and open access by the Animal Science Department at DigitalCommons@University of Nebraska - Lincoln. It has been accepted for inclusion in Faculty Papers and Publications in Animal Science by an authorized administrator of DigitalCommons@University of Nebraska - Lincoln. 


\title{
Breeding and Genetics 3: Implications of Cloning for Breed Improvement Strategies
}

\section{Implications of Cloning for Breed Improvement Strategies: Are Traditional Methods of Animal Improvement Obsolete?}

\author{
L. D. Van Vleck ${ }^{1}$ \\ USDA, ARS, U.S. Meat Animal Research Center, A218 Animal Sciences, \\ University of Nebraska, Lincoln 68583-0908
}

ABSTRACT: Can the optimum animal be defined? Will that definition change over time, by location, by market demand? First, assume what may be impossible, that the perfect animal can be defined or that only a limited number of definitions of "perfect" are needed. Then, can the "perfect" animal to match a definition be found? Suppose such an animal is found. Then the question to be answered before trying to clone as a method of genetic improvement becomes "Is the animal perfect because of phenotype or genotype?" In other words, the $P=G+E$ problem exists, which requires traditional methods of genetic evaluation and testing to determine whether genotype ( $G$ ) or random environmental ( $E$ ) effects or a combination leads to the apparent perfection in the phenotype $(P)$. For most traits, additive genetic variance accounts for 10 to $50 \%$ of total variance, a fraction denoted as heritability. With a simple model, the best prediction of genotypic value is to reduce the apparent phenotypic superiority by multiplying by heritability. Cloning the "perfect" animal also could capture optimum dominance and epistatic genetic effects that are otherwise difficult to select for. For some traits, maternal effects are important. In that case, clones as breeding animals must be "perfect" for both direct and maternal genotypes, or alternatively terminal and maternal clone lines would need to be developed. The use of clones to increase uniformity can be only partially successful. If heritability is $25 \%$, then the standard deviation among clones would be $87 \%$ of that of uncloned animals. Only if heritability is $100 \%$ will clone mates have complete uniformity. Fixing the genotype could increase susceptibility to failure if environment changes or if the cloned genotype is susceptible to a new disease or if economic conditions change. Cloning, at best, is another tool for animal improvement that joins the list of previous biotechnological inventions, some of which have become costeffective, such as artificial insemination, sexing of semen, multiple ovulation and embryo transfer, embryo sexing, and in vitro fertilization. Cloning has a place in that inventory but, in the long-term, the use of cloning will need to be managed to be cost effective for the improvement of quantitative characters.

Key Words: Genetics, Livestock, Animal Breeding

(c)1999 American Society of Animal Science and American Dairy Science Association. All rights reserved.

\section{Introduction}

Cloning, on first impression, suggests a perfect way to improve the performance of farm animals. As with many first impressions, the wrong conclusions are often drawn. These first impressions might be 1) that

\footnotetext{
${ }^{1}$ To whom correspondence should be addressed: A218 Animal Sciences, University of Nebraska, Lincoln 68583-0908 (phone: 402/ 472-6010; fax: 402/472-6362; E-mail: ansc418@unlvm.unl.edu).
}

clone mates (referred to as members of the clone) are identical in all respects, that is, are uniformly the same, and 2) that how clones will perform is known exactly. Another related impression is that superior records of the clone originator would guarantee that all members of the clone are genetically superior to other animals. Such first impressions would seem to imply that what breeders need to do is to find the perfect animal so that no further effort to breed better animals would be needed, that is, when the perfect animal is found, and cloned, then traditional methods 
of breed improvement would be obsolete. The purpose of this article is to show that these perceptions of cloning technology are generally incorrect and that traditional methods of animal improvement and genetic evaluation will be needed for effective implementation and for the economic evaluation of costs and expected returns.

\section{Discussion}

Many papers have discussed implementation of cloning for livestock improvement since 1980 (e.g., Van Vleck, 1981; Nicholas and Smith, 1983; Smith, 1989; Woolliams, 1989a,b; McClintock and Nicholas, 1991; Colleau, 1992; de Boer, 1994; Villanueva and Simm, 1994; Villanueva et al., 1998). An understandable history and stimulating discussion of the biological potentials of cloning can be found in Seidel (1983).

The approach here will be to illustrate some of the quantitative principles involved in refuting the incorrect perceptions listed in the introduction. Generally, these principles do not depend on whether cloning is from embryo splitting or from nuclear transfer of embryonic or adult cells except that adults may al ready have phenotypic measurements available. The most advantageous situation is to know the phenotype before cloning. The breakthrough that enables the cloning of adult animals is basically the reason for this symposium (Wilmut et al., 1997). Therefore, that situation will be the basis for most of the following illustrations.

\section{Are clones identical?}

This question has three answers: yes, unless, and no. Yes, the nuclear genetic material is the same. That would be true, unless, for example, mutation has occurred in cells from the clone originator, or unless cytoplasmic genetic material is considered, which may be different for each clone member in the case of nuclear transfer. Even in the case of embryo splitting, differences in cytoplasmic material may exist. No, the phenotypes will not be identical except for simply inherited characteristics, such as horns or lack of horns and base coat color. For characteristics of greatest importance, such as measures of performance, the phenotypes will not be identical and, in fact, in some cases other kinds of relatives may be more alike than clone members.

The basis for understanding the yes and no answers is the simple model used by animal breeders for quantitative traits, such as birth weight, lactation yield, or area of longissimus muscle:

$$
P=M A N+G+E
$$

where $\mathrm{P}$ is the phenotypic measure for a trait observed for an animal; $G$ is the sum of the effects of all the genes an animal has for that trait; $E$ is the sum of all nonattributable (random) environmental effects contributing to $\mathrm{P}$; and MAN is the combination of fixed factors, such as age, sex, and contemporary group, that contribute to $P$.

The model can easily be expanded. For example, G can be the sum of additive and dominance genetic effects as well as other kinds of genetic effects. For traits that can have repeated measures, such as lactation yield or litter weight weaned, $\mathrm{E}$ is often broken into a permanent environmental effect, which is not additive genetic but is associated with the animal and contributes to each record of an animal, and into a temporary environmental effect, which is the sum of nonattributable random environmental effects for a particular measurement. For traits influenced by mothering ability, such as weaning weight, $\mathrm{E}$ contains 1 ) the effects of the genotype of the mother for mothering ability (maternal G; usually, mostly milk production), 2) an effect comparable to the permanent environmental effect, the maternal permanent environmental effect (effect of permanent environmental factors on mothering ability of the dam) and 3) remaining nonattributable random temporary environmental effects. A model might also contain a cytoplasmic effect associated with elements in the cytoplasm transmitted in haploid fashion from female to female (also from female to male but not from male to female). Such models can be used to develop measures of uniformity or likeness between performance of pairs of members of a clone or between performance of pairs of other relatives or of pairs of unrelated animals.

One advantage often attributed to cloning is uniformity of performance, the "like peas in a pod" idea, which may be important for marketing or processing. If performance is the same, then the difference in pairs of records would be zero. The usual statistical measure of average differences is the variance of the difference, which is then converted to the standard error of the difference. When the records are identical, the standard error of the difference is zero. For example, if

$$
\text { Difference }=\underset{\text { Record of Animal } 1-\text { Record of }}{\text { Animal } 2}
$$

then the standard error of difference is

$$
\sqrt{\text { V(Record Animal } 1-\text { Record Animal 2) }}
$$

where $V(R e c o r d ~ 1-R e c o r d ~ 2)$ is the variance of the difference between Records 1 and 2 . 
First, the records are adjusted for the MAN parts. The square root of the variance of the remaining difference is in units of the trait and can be expressed in units of phenotypic standard deviations of the trait. The standard error of the difference is zero when the records are identical and is $\sqrt{2}$ times the phenotypic standard deviation for differences between records of unrelated animals. The factors that make the standard error of the difference small are the same factors that make the records similar. In the case of clone mates, the sum of all genetic effects, which might be called the clonal value (Smith, 1989), is what makes the records similar. The correlation between clone mates would be $\mathrm{H}^{2}$, which is comparable to heritability in the broad sense. If only additive genetic effects contribute to likeness, then the correlation is $h^{2}$, which is heritability in the narrow sense. In most of the following examples, $h^{2}$ will be used, but, if nonadditive genetic effects are important, then they would also need to be considered in the calculations. For the varied examples, standardized phenotypic standard deviations will be used $(\sigma=1)$. Conversion to a specified trait is to multiply by the phenotypic standard deviation for that trait.

With only additive genetic effects, the following are standard errors of differences between records of pairs of relatives with $\sigma=1$.

Clone mates:

Full-sibs:

$$
\text { SE difference }=\sqrt{2-2 \mathrm{~h}^{2}}
$$

$$
\text { SE difference }=\sqrt{2-\mathrm{h}^{2}}
$$

Half-sibs:

$$
\text { SE difference }=\sqrt{2-\mathrm{h}^{2} / 2}
$$

Unrelated pair:

$$
\text { SE difference }=\sqrt{2}
$$

If variance of dominance genetic effects contributes to genetic likeness by a fraction, $d^{2}$, then for

Clone mates:

$$
\text { SE difference }=\sqrt{2-2 \mathrm{~h}^{2}-2 \mathrm{~d}^{2}}
$$

Full-sibs:

$$
\text { SE difference }=\sqrt{2-h^{2}-d^{2} / 2}
$$

with standard error of the other differences not affected by dominance effects. The principle is that unless $d^{2}$ is large and $h^{2}$ is large, the reduction in the standard error of the difference for pairs of records of a cloned group is not great, as shown in Table 1. For example, with $\mathrm{h}^{2}$ of .50 , which is larger than for most traits, this measure of uniformity is only $30 \%$ better than for unrelated animals. Such an increase may or may not be enough to be economically important. Many people talk about uniformity, but apparently no one has assigned an economic value to uniformity. Usually what is meant by the term "uniformity" is the peas-in-a-pod concept of complete identity. Table 1 shows that for most traits, the peas in a pod are not all that uniform. The exception is for traits with nearly perfect broad-sense heritability. A trait such as amount of white spotting in Holstein cattle, which has high heritability in the narrow sense, could be cloned to create the peas-in-a-pod effect for appearance. The economic value of that kind of uniformity is likely to be more psychological than real. In summary, clone mates would be somewhat more uniform for performance than other pairs of relatives but would not be as uniform as most people would expect. With heritability of .20 or less, the increased uniformity generally would not be very noticeable. An advantage for clones, however, is that the number of animals in a clone may not be as limited as the number in a group of full-sibs, that is, the uniformity can be extended over a larger group of animals.

\section{Are clones superior?}

Again, the correct answer can be one or more of three choices: yes, maybe, or no. There is no sure way to identify superior animals except by testing many clone mates or by testing many progeny of a bull, for example. The usual, but perhaps incorrect, perception would be that an animal with a high record or other desirable attributes could be safely selected to be the origin of a family of clone mates. In the most simple

Table 1. Relative standard error of differences between pairs of records of relatives $(\sigma=1)$

\begin{tabular}{lcccc}
\hline \hline Heritability & Clones & Full-Sibs & Half-Sibs & Unrelated \\
\hline .00 & 1.41 & 1.41 & 1.41 & 1.41 \\
.20 & 1.26 & 1.34 & 1.38 & 1.41 \\
.50 & 1.00 & 1.22 & 1.32 & 1.41 \\
.80 & .63 & 1.10 & 1.26 & 1.41 \\
1.00 & .00 & 1.00 & 1.22 & 1.41 \\
\hline
\end{tabular}


case, the genotypic value of a clone originator can be predicted from the animal's record as

$$
\hat{g}=h^{2}(\text { Record }- \text { MAN })
$$

where MAN is the adjustment for the fixed factors affecting the record. If $\mathrm{H}^{2}>\mathrm{h}^{2}$, then replace $\mathrm{h}^{2}$ with $\mathrm{H}^{2}$ in what follows. The accuracy of the prediction is

$$
\text { Accuracy }=\sqrt{\mathrm{h}^{2}}
$$

The prediction error variance for genetic value is (where $\mathrm{g}$ is true and $\hat{g}$ is predicted genetic value)

$$
V(g-\hat{g})=\left(1-h^{2}\right) h^{2} \quad \text { when } \sigma=1
$$

The standard error of prediction ( SEP) is

$$
\sqrt{\left(1-h^{2}\right) h^{2}} \text { also when } \sigma=1
$$

Thus, if $\mathrm{h}^{2}$ (or $\mathrm{H}^{2}$ ) is not close to 1 , the SEP of genetic value can be quite large.

What is more important to the purchaser of a clone mate is likely to be the prediction of a record of a clone mate as a difference from effects of whatever fixed factors might affect the record, MAN. The prediction of a record of a clone mate (CM) based on a record of the clone originator (OR) is

$$
P_{C M}=h^{2}\left(P_{O R}-M A N\right)
$$

to which would be added estimates of fixed factors. The accuracy of prediction of such a record is $h^{2}$ (or $\mathrm{H}^{2}$ ), which is actually smaller than the accuracy of predicting genetic value; that is, for $h^{2}=.25, \sqrt{h^{2}}=.50$. The SEP for a record is $\sqrt{1-\left(\mathrm{h}^{2}\right)\left(\mathrm{h}^{2}\right)}$ when $\sigma=1$. The SEP for a record is much larger than the SEP for the genetic or clonal value because the $E$ part of a record is random and cannot be predicted before the record is made. These SEP are illustrated in Table 2 for various values of $h^{2}$. The SEP for a record of a new clone mate is not greatly different from the phenotypic standard deviation of any record. An important point, however, is that the standard error of prediction of the record of the clone mate is centered around the predicted record of the clone mate, which can be substantially above the average of the unselected population.

Genotypes of Parents Known Exactly. Suppose that instead of knowing a record of the clone origin, the genetic values of both parents ( $S$ and $D$ ) were known exactly (accuracy $=1$ for both), then

$$
\hat{g}=\left(g_{S}+g_{D}\right) / 2
$$

The accuracy of predicting genetic value, $r_{\hat{g}, g}$, is not 1.00 but .71 (Table 3). Then the SEP for genetic value is $\sqrt{(1-.5) \mathrm{h}^{2}}$ for $\sigma=1$. Similarly, the SEP for a record of a new clone mate (which is $\sqrt{1-h^{2} / 2}$ for $\sigma$ $=1$ ) never becomes less than . $71 \sigma$, even with $h^{2}=1$. This result and the previous examples show that records of clones of adult animals are not going to be exactly the same as a record of the adult originator. A producer will generally not know very well what is being purchased genetically and certainly will not know well at all what an individual clone mate will produce. However, the average of a large group of clone mates could be predicted very well.

Inbred Clones. Some increase in the correlation between records of clone mates can be achieved if the clone originator is inbred. With corn, the inbred lines are completely inbred with inbreeding coefficient, $\mathrm{F}=$ 1. Even then the correlation between records of clone mates is not $100 \%$ and is determined by whether $h^{2}$ is close to 1 . For $F=1$ (completely inbred), the correlation between records of pairs of clone mates is

$$
\begin{aligned}
r & =2 h^{2} /\left(h^{2}+1\right) \text { and } \\
\text { for } F & =0 \text { (not inbred) } r=h^{2}
\end{aligned}
$$

Table 4 shows that complete inbreeding does add to the correlation between clone mates depending on heritability. Inbred lines of corn are raised in plots, and the number of plants per plot is large enough that correlations between plots of the same line are essentially 1.00 when $F=1$.

With Maternal Effects. For traits such as weaning weight or birth weight in some species, maternal effects complicate the questions of uniformity and superiority of the clone originator. The basic model becomes

Table 2. Standard errors of prediction $(\sigma=1)$ of genotypic value of the clone and of the phenotype of a new member of the clone given phenotype of clone originator

\begin{tabular}{lcc}
\hline \hline Heritability & $\begin{array}{c}\text { Genotypic } \\
\text { value of clone }\end{array}$ & $\begin{array}{c}\text { Phenotype of new } \\
\text { clone mate }\end{array}$ \\
\hline .00 & $.00\left(\sigma_{\mathrm{g}}=0\right)$ & 1.00 \\
.20 & .40 & .98 \\
.50 & .50 & .87 \\
.80 & .40 & .60 \\
1.00 & $.00\left(\sigma_{\mathrm{e}}=0\right)$ & .00 \\
\hline
\end{tabular}


Table 3. Standard errors of prediction $(\sigma=1)$ of genotypic value of the clone and of the phenotype of a new member of the clone if parental genotypes are known exactly

\begin{tabular}{ccc}
\hline \hline Heritability & $\begin{array}{c}\text { Genotypic } \\
\text { value of clone }\end{array}$ & $\begin{array}{c}\text { Phenotype of new } \\
\text { clone mate }\end{array}$ \\
\hline .00 & $.00\left(\sigma_{\mathrm{g}}=0\right)$ & 1.00 \\
.20 & .32 & .95 \\
.50 & .50 & .87 \\
.80 & .63 & .77 \\
1.00 & $.71\left(\sigma_{\mathrm{e}}=0\right)$ & .71 \\
\hline
\end{tabular}

$$
P_{i}=M A N+a_{i}+m_{d_{i}}+p_{d_{i}}+e_{i}
$$

where $a_{i}$ is the direct genetic effect of the animal $i$ on its record; $m_{d_{i}}$ is the maternal genetic effect of the "mother" of animal $i, d_{i}$, on the record; and $p_{d_{i}}$ is the maternal permanent environmental effect associated with $d_{i}$. With usual reproduction systems, $d_{i}$ is the biological mother of animal i. With cloning, the surrogate mother, $d_{i}$, will be unrelated to animal $i$, and, more importantly, each clone member will likely have a different surrogate mother. In the absence of nonadditive genetic effects, the correlation between records of clone members will be $\mathrm{a}^{2}$ or direct heritability. The correlation between records of fullsibs will be $.5 a^{2}+m^{2}+(a m)+p^{2}$, where $m^{2}$ is maternal heritability, (am) is the standardized covariance between direct and maternal genetic effects, and $p^{2}$ is the proportion of variance accounted for by maternal permanent environmental effects. The correlation between maternal half-sibs will be $.25 \mathrm{a}^{2}+\mathrm{m}^{2}+$ $(a m)+p^{2}$. Thus for traits with maternal heritability large relative to direct heritability, the records of fullsibs and maternal half-sibs may be more similar than records of clone mates. The size of a clone family, however, may be much larger than full or maternal half-sib families.

Selection of a clone originator for direct effects would require a genetic evaluation system that can predict additive genetic value after adjustment for $m$ and $p$ effects. Similarly, selection of a clone originator for maternal effects (see later) would require adjustment for additive direct genetic effects of progeny of potential maternal clone originators.

Cytoplasmic Effects. Extranuclear genetic material in the cytoplasm of the recipient of the nuclear material may affect the performance of clone members. The record of a potential clone originator may express not only its genetic makeup but also the makeup of its cytoplasm. If cytoplasmic effects are important, then choice of clone originator requires an adjustment of records for cytoplasmic origin because the cytoplasm of the clone origin in the case of nuclear transfer does not transfer with the nuclear genetic material. The nuclear recipient furnishes the cytoplasm. With embryo splitting, the cytoplasmic material is that of the donor, but, in repeated splitting the cytoplasmic material may not be the same for each of the "splits." Evidence for the importance of cytoplasmic effects is not consistent. With dairy cattle, the effects seem to be relatively minor within a breed for yield traits (Boettcher and Gibson, 1997; Albuquerque et al., 1998). Robison (1998), however, has shown what may be an interaction between breed direct genetic effects and breed cytoplasm in swine. The question of compatibility (interaction) of donor nuclear material and recipient cytoplasm would seem likely to be more important than a covariance between nuclear genetic and cytoplasmic effects.

Repeated Measure Traits. Lactation yield and litter weight weaned are traits that can be considered as repeated measures traits, although yields, for example, also could be considered different traits at different ages. The repeated measures model for record $j$ of animal $i$ even in that case is often a good approximation:

$$
P_{i j}=M A N+a_{i}+p_{i}+e_{i j}
$$

where now MAN may be different from record to record and $p_{i}$ is the permanent environmental effect associated with the animal (i) with the records. The implications to uniformity and to prediction of the value of the clone origin should be obvious. The correlation between a pair of records of the animal would be $a^{2}+p^{2}$, which is called repeatability, but between pairs of records of clone mates would only be $\mathrm{a}^{2}$ (heritability), as clone mates are not likely to have the same permanent environmental effects. An exception is if nonadditive genetic effects are included in $p_{i}$.

Table 4. Correlation between phenotypic records of pairs of clone mates with no $(\mathrm{F}=0)$ or complete inbreeding $(F=1)$

\begin{tabular}{lrc}
\hline \hline & \multicolumn{2}{c}{ Inbreeding } \\
\cline { 2 - 3 } Heritability & $\mathrm{F}=1$ & $\mathrm{~F}=0$ \\
\hline .00 & .00 & .00 \\
.20 & .33 & .20 \\
.50 & .67 & .50 \\
.80 & .89 & .80 \\
1.00 & 1.00 & 1.00 \\
\hline
\end{tabular}


If $p_{i}$ is, in fact, not environmental but is due only to dominance genetic effects, then the correlation between clones would be $a^{2}+d^{2}$. The true correlation between clone mates will have approximate bounds of $a^{2}$ and $a^{2}+p^{2}$. Estimates of $d^{2}$ and contributions of other nonadditive genetic effects to total variance are rare for most traits (Misztal et al., 1998).

For a cow with many lactations or a ewe or a sow with many litters weaned, the temptation is to believe that such females would be perfectly evaluated genetically. That would be another incorrect impression. The accuracy of prediction of genetic value with $n$ records of an animal is

$$
\sqrt{n a^{2} /\left[1+(n-1)\left(a^{2}+p^{2}\right)\right.}
$$

As $\mathrm{n}$ becomes large, accuracy tends in the limit to $\sqrt{a^{2} /\left(a^{2}+p^{2}\right)}$ For milk yield, $a^{2}$ and $p^{2}$ are roughly equal and about .25. In that case, accuracy in the limit is .71, not the perfect, 1.00 .

The standard error of prediction of the genetic value of a clone member would then be

$$
\operatorname{SEP}(a)=\sqrt{(1-.5) \mathrm{h}^{2}} \text { for } \sigma=1
$$

and the standard error of prediction of a record of a clone member would then be

$$
\operatorname{SEP}_{(p)}=\sqrt{1-h^{2} / 2} \text { for } \sigma=1
$$

If nonadditive genetic effects are important, then $\mathrm{H}^{2}$ would be substituted for $\mathrm{a}^{2}$ with $\mathrm{p}^{2}$ reduced correspondingly. For example, if $\mathrm{H}^{2}=\mathrm{a}^{2}+\mathrm{p}^{2}$, which is the upper limit for $\mathrm{H}^{2}$, then the limit for accuracy of prediction of clonal genetic value would be 1.00 when many records of the potential clone originator are available.

Clone a "Proved" Bull or Ram? The preceding discussion has implied that the clone families are female partly because success in cloning has been with females and partly because females are the productive dairy animals. However, as suggested by Smith (1989), beef cattle systems could use both "terminal" and "maternal" clones. Terminal clones that are males would seem preferred for growth traits. A bull can easily have a genetic proof with nearly perfect accuracy of 1.00 for the prediction of additive genetic value but not for clonal value. The standard error of prediction for clonal value would in that case be $\sqrt{\mathrm{H}^{2}-\mathrm{h}^{2}}$ for $\sigma=1$. Terminal clones of such a bull, however, would not be uniform unless broad-sense heritability was near unity. As before
SE (difference of clone records) $=\sqrt{2-2 \mathrm{H}^{2}}$
for $\sigma=1$

Calculations have been made (Wade et al., 1991; Goddard et al., 1994) that show clones of superior rams may be a cost-effective alternative to artificial insemination. In that case, the standard error of differences in clones would apply to all traits of the ram. Not only would additive genetic value for growth transmitted to progeny be important but also the individual performance of the male for traits such as fertility would be important. What the $\left(\sqrt{2-2 \mathrm{H}^{2}}\right) \sigma$ formula shows is that, for a low-heritability trait such as fertility, the performance of clone mates can be quite different. Direct fertility of a battery of cloned males might, in fact, be much more important than transmission of genetic value for growth to their progeny.

\section{Finding the Founder of the "Perfect" Clone}

The perception of clones being identical leads to a secondary impression that, if only the perfect animal could be found, then the clone mates of that perfect animal would also be ideal animals, with perfect performance. The previous discussion has shown the fallacies of expecting a high degree of uniformity among clone mates and of expecting the phenotypic superiority of the clone origin to predict equivalent genetic superiority. But suppose a perfect animal does exist that fits the ideal for a specific trait. What are the odds of finding such an animal? The following steps are not recommended but are used to show the futility of a direct approach. Assume what is needed is a superiority of three genetic standard deviations. A simple approach might be to locate all animals with records of plus four phenotypic standard deviations, which is at approximately the upper limit of credibility. Records above that limit often are viewed with suspicion and would routinely be deleted as outliers in statistical analyses or by practicing animal breeders. The basic fear is that such records are the result of preferential treatment of some kind. If that possibility is ignored, how many animals would qualify from this first step? According to the normal probability tables, about 32 animals per million would be expected to have a record exceeding the mean by four phenotypic standard deviations. With $\mathrm{h}^{2}=.25$, the predicted genetic value of an animal with a record of four phenotype standard deviations above the mean would be one phenotypic standard deviation or two genetic standard deviations (see previous formula) above the average of all animals. With the need to gain one more 
genetic standard deviation, the 32 qualifiers per million could be tested. With perfect genetic evaluations, 1 of 8 would be expected to be one genetic standard deviation above the mean of two genetic standard deviations. Thus, approximately four of each million animals might meet the standard for one trait. What about more traits? If the traits were independent, with the same $h^{2}$, and with same importance, the odds of finding an animal that is perfect for two traits would be 16 per $(1,000,000)^{2}$. The odds become more and more against perfection in all traits as the number of traits increases. Although this procedure is not optimized, the point is clear: finding an animal that meets high standards for several traits is unlikely. The perfect animal might exist, but finding such an animal and verifying the perfection is highly unlikely.

What needs to be added to this pessimistic but pragmatic outlook is the question of whether the "perfect" animal for one environment is the perfect animal for other environments. Environments can be considered locations, climates, economic systems, and the potential for future changes in biological conditions, prices, and costs.

This long prelude leads to the unsurprising conclusion that traditional methods for livestock improvement are not obsolete. In fact, those methods will be needed even more for complex genetic evaluations and for designing selection programs using cloning technology.

\section{Improvement Using Cloning} as a Reproductive Tool

One of the first considerations of cloning as a tool for genetic improvement was aired at a conference sponsored by the Office of Technology Assessment of the United States Congress nearly $20 \mathrm{yr}$ ago in Denver in J anuary of 1980, with proceedings published as New Technologies in Animal Breeding (Brackett et al., 1981). That first attempt viewed cloning as a deadend (Van Vleck, 1981). Soon after that, Nicholas and Smith (1983) and Hulle and Van Vleck (1984) realized a combination of progeny testing and clone testing could lead to continued progress.

One key point of their results is the initial "lift" that comes from the dissemination of clones of a few of the very best cows from the whole population to reproduce the cow population. A second lift comes from the initial testing of and selection from cloned progeny of those selected cows followed by a steady rate of improvement. Both papers expressed concern for the potential increase in rate of inbreeding.
What should also be of interest are the trend lines in the Nicholas and Smith (1983) paper denoting possible and achieved responses with progeny testing alone. The difference in those two lines suggests that the cost-effectiveness of traditional progeny-testing methods has not (and still has not) been fully utilized. Nevertheless, as many as $15 \mathrm{yr}$ ago, cloning was established to have the potential to increase the rate of genetic improvement.

Basic Equations for Predicting Genetic Improvement. Approximately 50 yr ago, Dickerson and Hazel (1944) and Robertson and Rendel (1950) outlined the basic equations needed to compare selection programs. A one-path simplification will be used to illustrate the usual trade-offs required to find the optimum:

\section{Gain/year = \\ $\frac{(\text { Accuracy)(Intensity factor)(Genetic SD) }}{\text { Generation interval (yr) }}$}

Because the genetic standard deviation (SD) is essentially a constant (modifications may be made for change due to selection and inbreeding), the three factors that generally must be balanced are the accuracy of identifying superior animals, the fraction of animals needed to be selected as parents (which determines the intensity factor assuming the normal distribution), and the time from when parents are born until their replacements are born (generation interval). These factors tend to be negatively but not linearly associated; for example, an increase in accuracy may lead to fewer animals available for selection (a smaller selection intensity factor) and to a larger time interval between generations due to the delay in getting more information to increase the accuracy of the genetic evaluation.

Many reproductive technologies have been studied for potential impact on genetic improvement but few have been widely used. The major success story for dairy cattle involves artificial insemination. Other technologies considered have been semen sexing, multiple ovulation and embryo transfer, in vitro fertilization, embryo sexing, and cloning both by embryo splitting and nuclear transfer. Several economic considerations are involved in such studies, and they include size of population to improve, testing resources, planning horizon, discount rate, and-most importantly-expected income vs expected costs. Although several of these technologies would seem to have the potential to increase rates of genetic improvement, none except artificial insemination has been widely or completely adopted, probably because of risk of not recovering costs in a relatively short 
period of time (e.g., Van Vleck and Everett, 1976).

Games Animal Breeders Play. Generally, resources for testing animals are limited. Therefore, accuracy must be balanced against intensity of selection. The following simplified version of this game illustrates the concept. First consider the accuracy of predicting additive genetic value if $\mathrm{n}$ members of a clone are tested. Assumed will be heritability of .25 and three levels of fraction of total variance due to dominance genetic effects $(.00, .10, .25)$. The range for relative variance due to dominance effects easily encompasses estimates summarized by Misztal et al. (1998). With only additive genetic effects, $a$, and dominance genetic effects, $d$, the accuracies of prediction are

For additive genetic value:

$$
\operatorname{Acc}(a)=\sqrt{(n) /\left[1+(n-1)\left(a^{2}+d^{2}\right)\right]}\left(\sqrt{ } a^{2}\right)
$$

For clonal (additive plus dominance genetic) value:

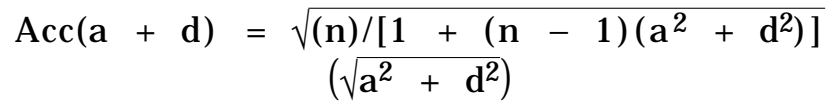

For a record of new clone member:

$$
\begin{gathered}
A c c(P)=\sqrt{(n) /\left[1+(n-1)\left(a^{2}+d^{2}\right)\right]} \\
\left(a^{2}+d^{2}\right)
\end{gathered}
$$

Calculations are shown in Table 5 for the example. If selection is for additive genetic value, accuracy will go to 1.00 with enough clone numbers tested if $d^{2}$ is zero (top of Table 5). If $d^{2}$ equals $a^{2}$, then the limit for accuracy is .71. The principle is that likeness due to dominance effects is interfering with selection for additive effects.

With cloning, the emphasis for selection will generally be on clonal value rather than on additive genetic value alone. The middle of Table 5 shows that the greater $a^{2}+d^{2}$ is, the greater the accuracy for predicting clonal value.

The bottom of Table 5 shows that even with many tested clone members, the accuracy of prediction of a record of new clone member never becomes perfect. The SEP becomes smaller for larger $d^{2}$ and for increasing number of clone members tested, but complete uniformity for records of clone members is not attained (Table 6).

Table 7 illustrates combining accuracy and intensity of selection. In the simplified example, 100 spaces are available for testing. The question is how to allot those spaces between number of different clones
Table 5. Accuracy of clone proofs for numbers of clone members tested $\left(\mathrm{h}^{2}=.25 ; \mathrm{d}^{2}=.00, .10, .25\right)$

\begin{tabular}{lccc}
\hline \hline $\begin{array}{l}\text { No. } \\
\text { tested }\end{array}$ & $\mathrm{d}^{2}=.00$ & $\mathrm{~d}^{2}=.10$ & $\mathrm{~d}^{2}=.25$ \\
\hline & Accuracy of prediction of additive genetic value - \\
1 & .50 & .50 & .50 \\
2 & .63 & .61 & .58 \\
3 & .71 & .66 & .61 \\
5 & .79 & .72 & .64 \\
7 & .84 & .75 & .66 \\
10 & .88 & .78 & .67 \\
& Accuracy of prediction of clonal value \\
1 & .50 & .59 & .71 \\
2 & .63 & .72 & .82 \\
3 & .71 & .79 & .87 \\
5 & .79 & .85 & .91 \\
7 & .84 & .89 & .94 \\
10 & .88 & .92 & .95 \\
& - Accuracy of prediction of record of new clone member - & .50 \\
1 & .25 & .35 & .58 \\
2 & .32 & .43 & .61 \\
3 & .35 & .46 & .64 \\
5 & .40 & .50 & .66 \\
7 & .42 & .53 & .67 \\
10 & .44 & .54 & \\
\hline
\end{tabular}

(genotypes) and number to test in each clone. Four possibilities are shown. Table 7 shows expected clonal response $(a+d)$ in one generation. Table 7 shows that as $d^{2}$ becomes larger, the emphasis should be on testing more unique clones but with only one or two clone members tested. With smaller $d^{2}$, more members per clone should be tested at the expense of fewer unique clones. As expected, larger $\mathrm{a}^{2}+\mathrm{d}^{2}$ leads to greater clonal response than with smaller $d^{2}$.

The right side of Table 7 shows expected additive genetic response for the combinations of number tested per clone and number of clones. Although the optimum combinations are the same as for clonal response, the patterns are different. Increase in $d^{2}$

Table 6. Standard error of predicting a record of new clone member $\left(h^{2}=.25, \sigma=1\right)$

\begin{tabular}{cccc}
\hline \hline No. tested & $\mathrm{d}^{2}=.00$ & $\mathrm{~d}^{2}=.10$ & $\mathrm{~d}^{2}=.25$ \\
\hline 1 & .97 & .94 & .87 \\
2 & .95 & .90 & .82 \\
3 & .94 & .88 & .79 \\
5 & .92 & .86 & .76 \\
7 & .91 & .85 & .75 \\
10 & .90 & .84 & .74 \\
\hline
\end{tabular}


Table 7. Expected clonal and additive genetic responses for an example of clone testing with 100 test stalls, $\mathrm{h}^{2}=.25$

\begin{tabular}{|c|c|c|c|c|c|c|c|c|}
\hline \multirow{2}{*}{$\begin{array}{l}\text { No. tested/ } \\
\text { clone }\end{array}$} & \multirow{2}{*}{$\begin{array}{c}\text { No. } \\
\text { genotypes } \\
\text { tested } \\
\end{array}$} & \multirow{2}{*}{$\begin{array}{c}\text { If select one, } \\
\text { intensity } \\
\text { factor }\end{array}$} & \multicolumn{3}{|c|}{ Clonal response $(\sigma=1)$} & \multicolumn{3}{|c|}{ Additive response $(\sigma=1)$} \\
\hline & & & $d^{2}=.00$ & $d^{2}=.10$ & $d^{2}=.25$ & $d^{2}=.00$ & $d^{2}=.10$ & $d^{2}=.25$ \\
\hline 10 & 10 & 1.54 & .68 & .84 & 1.04 & .68 & .60 & .52 \\
\hline 5 & 20 & 2.06 & .81 & 1.04 & 1.33 & .81 & .74 & .66 \\
\hline 2 & 50 & 2.42 & .76 & 1.03 & 1.40 & .76 & .74 & .70 \\
\hline 1 & 100 & 2.66 & .66 & .93 & 1.33 & .66 & .66 & .66 \\
\hline
\end{tabular}

leads to less response in additive genetic value because clone members have records that are proportionally more alike due to dominance effects, which leads to failure to separate effectively dominance and additive genetic values.

Actual studies to optimize breeding plans are obviously more complicated than for this simple game due to more factors being considered simultaneously, to accounting for decrease in genetic variance, to restriction on amount of inbreeding allowed, and to obtaining break-even costs (e.g., Teepker and Smith, 1989; Woolliams, 1989a,b; Keller et al., 1990; de Boer and van Arendonk, 1991; Colleau, 1992; de Boer et al., 1994; Villanueva et al., 1998). Most studies have shown an advantage for genetic and clonal improvement from incorporating cloning into a breeding plan although none has shown a very low break-even cost (de Boer, 1994; Dematawewa and Berger, 1998).

\section{Some Questions}

Concerns involving a reliance on cloning technology include the following. One concern is a build-up of inbreeding. With relatively slow genetic change and fewer "eggs in one basket," selection can often overcome effects of inbreeding. With rapid change, that flexibility may be lost. Perhaps cloning or molecular techniques can be developed to test for and eliminate deleterious recessive genes, which might effectively eliminate the concern with inbreeding.

A second concern is related to "all eggs in one basket." Rapid change with few effective genotypes could lead to a limited ability to adapt to new disease problems and to changes in environmental conditions (for example, for a switch from a concentrate-based to a forage-based feeding system). Similarly, if economic situations change (for example, if the fat differential for milk pricing doubles or triples or the reverse occurs as it has, in both directions, over the past $20 \mathrm{yr}$ ) and the breeding program is headed in another direction, it is difficult and inefficient to change emphasis on economic traits very quickly.
Some biological questions may also need to be answered. With the transfer of adult nuclear material, will age-related mutations build up? Will some tissues be more protected than others from somatic mutations? After many cell divisions, the starting genome seems unlikely to have remained exactly intact. Are there ways to test the importance of such questions? The efficiency of nuclear transfer has to increase dramatically to have enough data to attack such problems. The question of compatibility of cytoplasm and nuclear material was raised earlier but remains to be answered.

A topic also raised earlier leads to one final set of questions. Smith (1989) proposed that a two-line cloning system would be most effective for beef cattle. Clones selected as terminal animals would be used for marketing but would be gestated and raised by clones selected for maternal ability. This might be a solution to the dilemma that beef cattle breeders have struggled with in the past: to have calves that grow fast to a high-quality market product but to have small cows with little calving difficulty and plenty of milking ability (i.e., large, heavily muscled calves and small dairy cows). This idea brings costs back into the discussion. The genetic value of each terminal calf would be expressed only once from the use of cloning technology; that is, one big male calf per embryo transfer of a cloned genotype. The cost of cloning, however, is likely to be the same as for a one-time embryo transfer to produce a cow that would produce several calves or several lactations. A major cost of cloning (except for losses due to inefficiencies, which would need to be overcome in any case for cloning to be worthwhile for genetic improvement) would be for embryo transfer. The question is how small that cost can become.

\section{Summary}

1. Much work will be needed using traditional animal-breeding techniques (genetic evaluation, 
breeding plans) to incorporate cloning technology into commercial livestock systems.

2. The value of cloning is greatest when clonal variance is large relative to additive genetic variance. In fact, cloning is about the only effective way to utilize nonadditive genetic effects in a selection program.

3. Cloning makes the traditionally most-suspect paths of selection even more vulnerable to misleading records caused by deliberate or chance preferential treatment. Controlled testing in nucleus systems can guard against such problems, or, if manipulated, it could aggravate such problems.

4. Cloning could provide faster dissemination of superior genetic material to the population than has previous plans. A quote from Smith (1989) emphasizes this point. "One result would be that commercial animals could be genetically superior to the breeding animals. Thus, it can be said that cloning could turn the conventional breeding pyramid on its head."

5. Clones are quite simply just another kind of genetic family about which more knowledge is needed (the importance of nonadditive genetic effects, of cytoplasmic effects, of somatic mutations of genetic by environmental interactions).

6. Finally almost, who can afford the start-up and carrying costs of such a program? Most corporations seem to put more emphasis on short-run than on long-term goals. Can this technology be made inexpensive enough to compete with a mature technology, such as artificial insemination, or with a niche technology, such as multiple ovulation and embryo transfer? For example, a farm writer (Guebert, 1998) asked this set of questions: Will a dairy farmer in a decade or so buy a set of 100 or even a 1,000 uniform-actually identical-cloned, two-year-old Holsteins from an Internet catalog ordered by e-mail? How will the contract be written? Who owns the milk produced? Who owns the breeding rights? Will a profit be left for the farmer? These are some of the ethical, legal, and economics questions that will need to be addressed.

A cautious writer for Dairy Herd Management should receive credit for the final comment. Some writers are not normally cautious in telling stories, but this writer certainly had digested all of what he had gathered to write an article on cloning with the following title (Flaherty, 1997): Cloning Won't Amount to Much Very Soon.
Nevertheless, potential applications and challenges of cloning technology should continue to be evaluated using principles underlying traditional methods of animal improvement.

\section{Implications}

Cloning, on first impression, suggests a perfect way to improve performance of farm animals. These first impressions might include the following. 1) Clone mates (members of the clone) are identical in all respects; that is, they are uniformly the same. 2) Clones are superior; that is, how they will perform is known exactly. 3) Superior records of the clone originator would guarantee that all members of the clone are superior to other animals. Such impressions imply that breeders need to find the perfect animal so that no further effort to breed better animals is needed; when the perfect animal is found and cloned, then traditional methods of breed improvement would be obsolete. These perceptions are generally incorrect for most important traits of livestock. Thus, traditional methods of animal improvement and genetic evaluation will be needed for the effective implementation and economic evaluation of cloning technology.

\section{Literature Cited}

Albuquerque, L, G., J. F. Keown, and L. D. Van Vleck. 1998. Variances of direct genetic effects, maternal genetic effects and cytoplasmic inheritance effects for milk yield, fat yield, and fat percentage. J. Dairy Sci. 81:544-549.

Boettcher, P. J ., and J. P. Gibson. 1997. Estimation of variance of maternal lineage effects among Canadian Holsteins. J . Dairy Sci. 80:2167-2176.

Brackett, B. G., G. E. Seidel, and S. M. Seidel (Ed.) 1981. New technologies in animal breeding. Academic Press, New York.

Colleau, J . J . 1992. Combining use of embryo sexing and cloning within mixed MOETS for selection on dairy cattle. Genet. Sel. Evol. 24:345-361.

de Boer, I.J.M. 1994. The use of clones in dairy cattle breeding. Ph.D. dissertation. Wageningen Agricultural University, The Netherlands.

de Boer, I.J .M., T.H.E. Meuwissen, and J .A.M. van Arendonk. 1994. Combining the genetic and clonal responses in a closed dairy cattle nucleus scheme. Anim. Prod. 59:345-358.

de Boer, I.J .M. and J .A.M. van Arendonk. 1991. Genetic and clonal responses in closed dairy cattle nucleus schemes. Anim. Prod. 53:1-9.

Dematawewa, C.M.B., and P. J. Berger. 1998. Break-even cost of cloning in genetic improvement of dairy cattle. J . Dairy Sci. 81: 1136-1147.

Dickerson, G. E., and L. N. Hazel. 1944. Effectiveness of selection on progeny performance as a supplement of earlier culling in livestock. J. Agric. Res. 69:459-476. 
Flaherty, M. 1997. Cloning won't amount to much very soon. Dairy Herd Manage. (J une):10-12.

Goddard, M. E., N. R. Wray, L. D. Brash, C. M. Wade, B. Gaffney, and F. W. Nicholas. 1994. The use of advanced breeding techniques in wool sheep breeding. Report to Autralian Wool Research and Promotion Organization. Dept. of Agriculture, Victoria, Melbourne.

Guebert, A. 1998. Questions, few answers for biotech and farmers. Lincoln J ournal Star (April 6):5B.

Hulle, L. R., and L. D. Van Vleck. 1984. Cloning embryos as a method of genetic improvement. In: Genetics Research 1983-1984 Report to Eastern Artificial Insemination Cooperative. Ithaca, NY. pp 210-220.

Keller, D. S., W. W. Gearheart, and C. Smith. 1990. A comparison of factors reducing selection response in closed nucleus breeding schemes. J. Anim. Sci. 68:1553-1561.

McClintock, A. E., and F. W. Nicholas. 1991. The impact of cloning on animal industries. Proc. Aust. Assoc. Anim. Breed. and Genet. 9:117-119.

Misztal, I., L. Varona, M. Culbertson, N. Gengler, K. Bertrand, J . Mabry, T. J. Lawlor, and C. P. Van Tassell. 1998. Studies on the value of incorporating effects of dominance in genetic evaluations of dairy cattle, beef cattle, and swine. Proc. 6th World Congr. Genet. Appl. Livest. Prod. 25:513-516.

Nicholas, F. W., and C. Smith. 1983. Increased rates of genetic change in dairy cattle by embryo transfer and splitting. Anim. Prod. 36:341-353.

Robertson, A., and J. M. Rendel. 1950. The use of progeny testing with artificial insemination in dairy cattle. J. Genet. 50:21-31.

Robison, O. W. 1998. Evidence for cytoplasmic influence on litter size in swine. Proc. 6th World Congr. Genet. Appl. Livest. Prod. 27:35-38.
Seidel, G. E. 1983. Production of genetically identical sets of mammals: Cloning? J . Exp. Zool. 228:347-354.

Smith, C. 1989. Cloning and genetic improvement of beef cattle. Anim. Prod. 49:49-62.

Teepker, G., and C. Smith. 1989. Combining clonal response and genetic response in dairy cattle improvement. Anim. Prod. 49: 163-169.

Van Vleck, L. D. 1981. Potential genetic impact of artificial insemination, sex selection, embryo transfer, cloning and selfing in dairy cattle. In: B. G. Brackett, G. E. Seidel, J r., and S. M. Seidel (Ed.) New Technologies in Animal Breeding. 241-242. Academic Press, New York.

Van Vleck, L. D., and R. W. Everett. 1976. Genetic value of sexed semen to produce dairy heifers. J . Dairy Sci. 59:1802-1807.

Villanueva, B., and G. Simm. 1994. The use and value of embryo manipulation techniques in animal breeding. Proc. 5th World Congr. Genet. Appl. Livest. Prod. 20:200-207.

Villanueva, B., J . A. Woolliams, and G. Simm. 1998. Evaluation of embryo sexing and cloning in dairy cattle nucleus schemes under restricted inbreeding. Proc. 6th World Congr. Genet. Appl. Livest. Prod. 25:451-454.

Wade, C., M. Goddard, B. Gaffney, and F. W. Nicholas. 1991. The potential value of cloned rams for use in commercial Merino flocks. Proc. Aust. Assoc. Anim. Breed. Genet. 9:113-116.

Wilmut, I., A. E. Schneike, J. McWhir, A. J. Kind, and K.H.S. Campbell. 1997. Viable offspring derived from fetal and adult mammalian cells. Nature 385:810-813.

Woolliams, J. A. 1989a. Modifications to MOET nucleus breeding schemes to improve rates of genetic progress and decrease rates of inbreeding in dairy cattle. Anim. Prod. 49:1-4.

Woolliams, J. A. 1989b. The value of cloning in MOET nucleus breeding schemes for dairy cattle. Anim. Prod. 48:31-35. 